\title{
Shawn Serfas en février et les enfants au travail
}

\section{Catherine Parayre}

En février 2016, des élèves des écoles Dalewood (immersion), Sacré-Cœur (francophone) et Sainte Marguerite Bourgeoys (francophone) de la région du Niagara sont venus au Musée d'art contemporain de Rodman Hall à St. Catharines. Ils y ont visité deux expositions : «Inland» (commissaire: Stuart Reid) de l'artiste canadien Shawn Serfas et «Visual Appropriations and Rewritings » (commissaires : Catherine Parayre et Shawn Serfas) montrant les œuvres d'étudiants de l'Ecole des arts Marilyn I. Walker de l'Université Brock à Saint Catharines. Les élèves, de huit à treize ans, ont réfléchi aux questions suivantes : Quelles sont les différences et les similarités entre l'art figuratif et l'art abstrait? Quels sont les avantages du travail collaboratif?

La magnifique exposition de Shawn est composée de grandes et petites toiles de peinture abstraite. Nous avons admiré la fusion d'éclatantes couleurs, les mouvements verticaux et circulaires de lignes vibrantes d'énergie, la peinture métamorphosée en sculptures d'amas et tubes colorés accrochés aux tableaux, l'immense défi technique chaleureusement résolu. Nous avons inventé de petites histoires en contemplant ces formes abstraites.

«Visual Appropriations and Rewritings » rassemble les travaux d'étudiants qui ont travaillé ensemble pendant tout un semestre pour produire des œuvres visuelles et littéraires. La collaboration est, ainsi, non seulement un échange entre des personnes, mais aussi un agencement d'images et de textes. Les travaux des étudiants sont disposés sur et autour des canevas d'un jaune vif que Shawn a disposés sur les murs pour faire écho à sa propre exposition $(\ll$ Inland $»)$ dans les salles adjacentes.

Après leur visite, les enfants se sont installés dans l'atelier d'art et ont composé leurs contributions aux thèmes abordés. Au bas d'une feuille blanche, chacune et chacun s'est inspiré des tableaux de Shawn et a dessiné une image abstraite. Puis, les feuilles ont changé de mains et la voisine ou le voisin de table a fait un dessin figuratif au choix sur la partie supérieure de la feuille.

Qu'en avons-nous conclu à la fin de la matinée ? Tout d'abord, le travail collaboratif est amusant et créatif et, ensuite, l'art abstrait et l'art figuratif, malgré leurs différences, partagent un même élan d'imagination.

Nous avons ensuite confié nos dessins à Shawn, qui a gentiment accepté d'en sélectionner certains pour les inclure dans ce catalogue. 


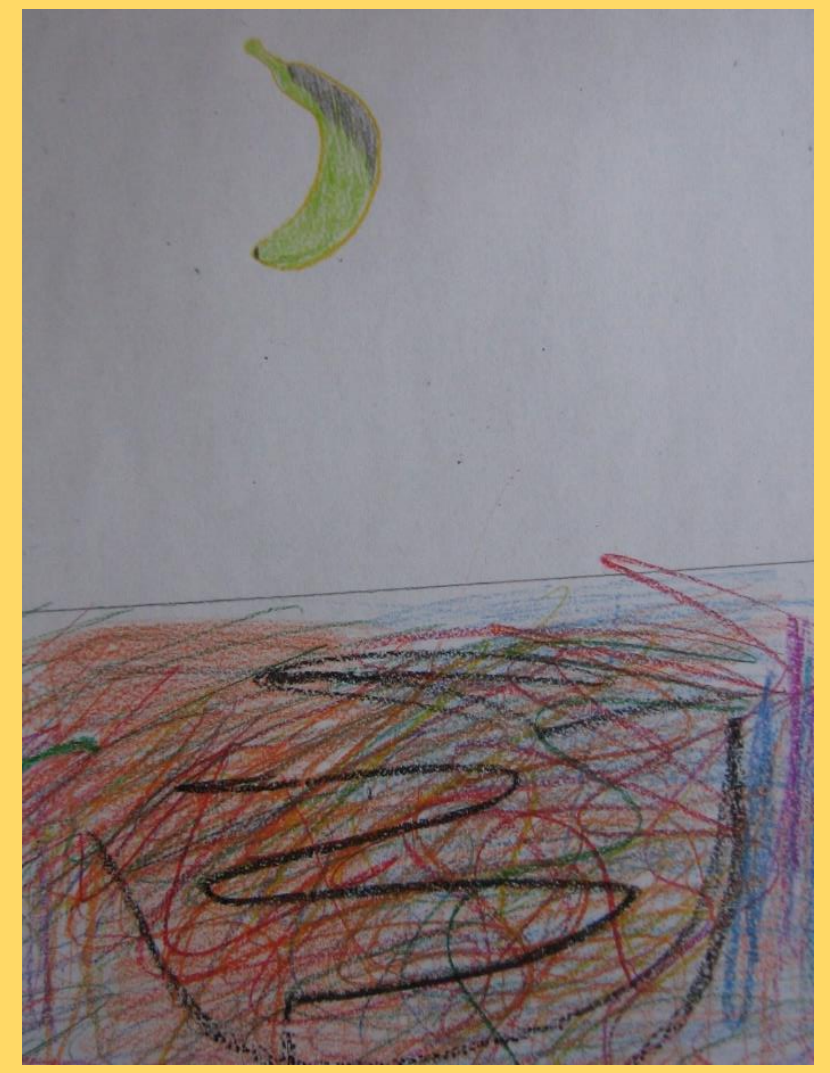


$t i<5.1(2016)$

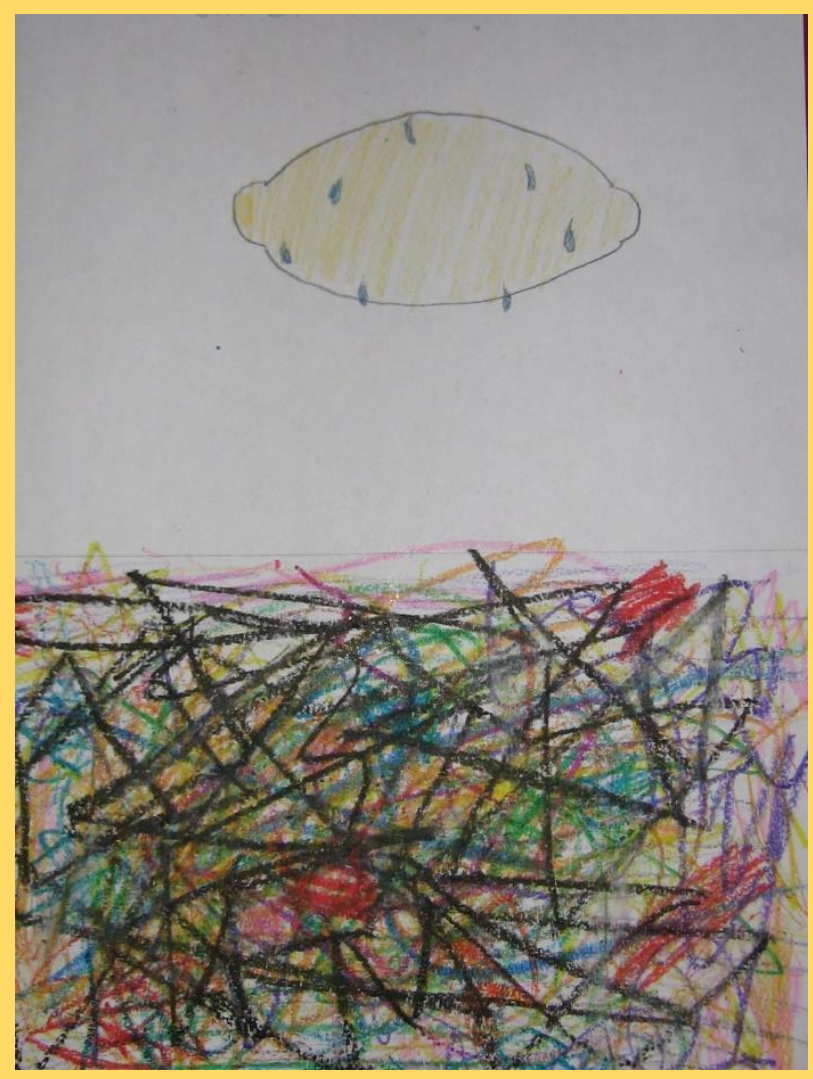



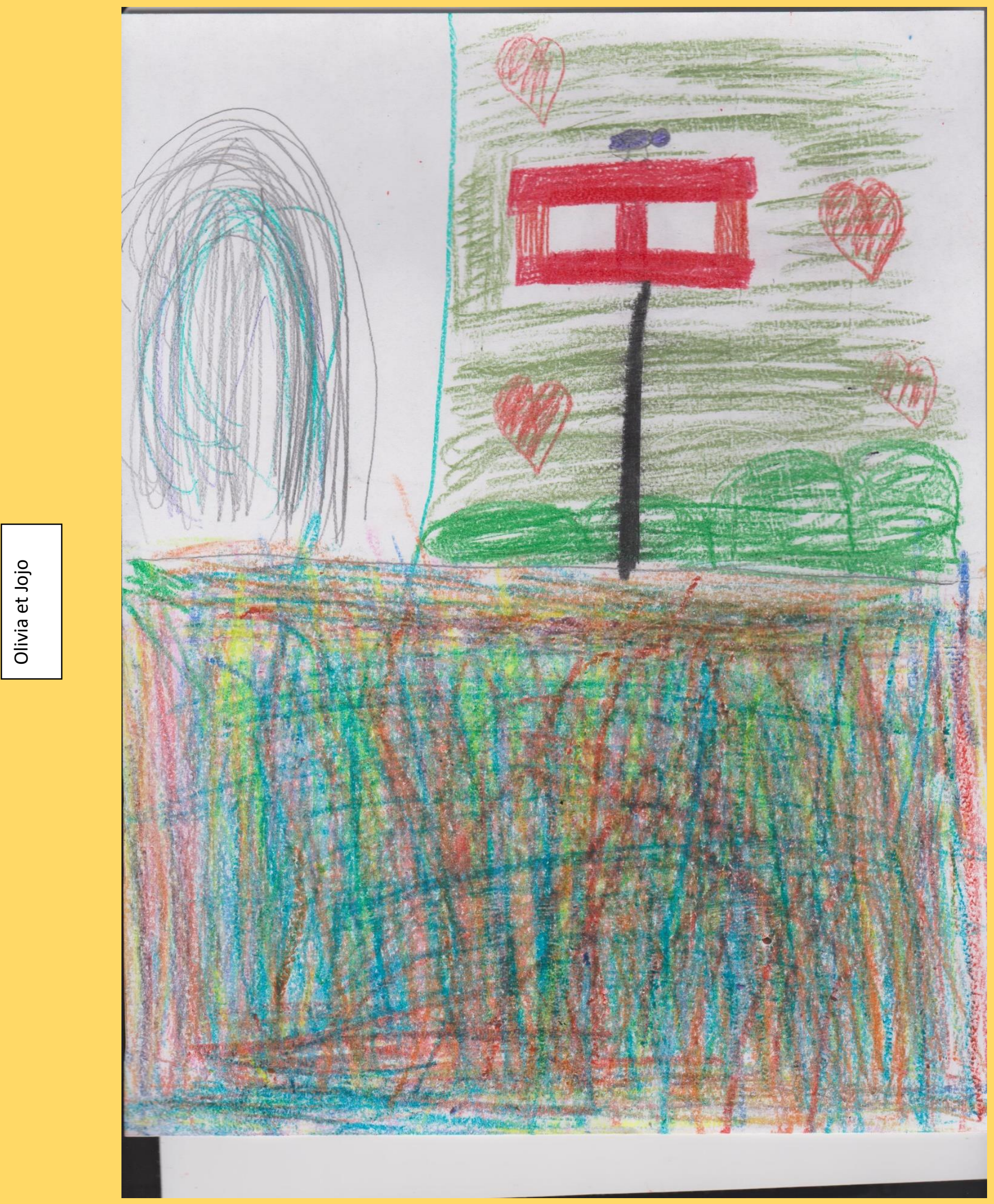


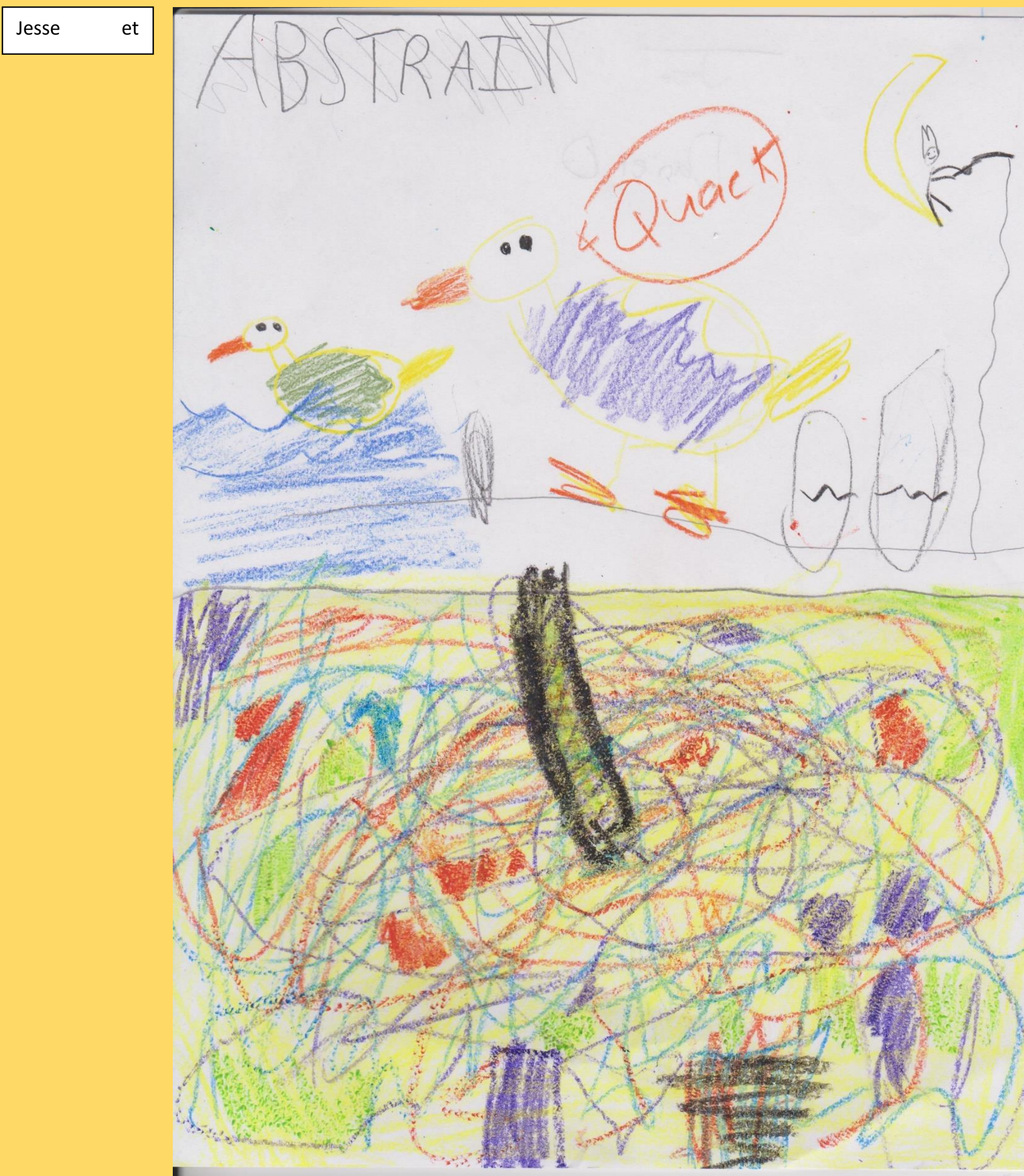




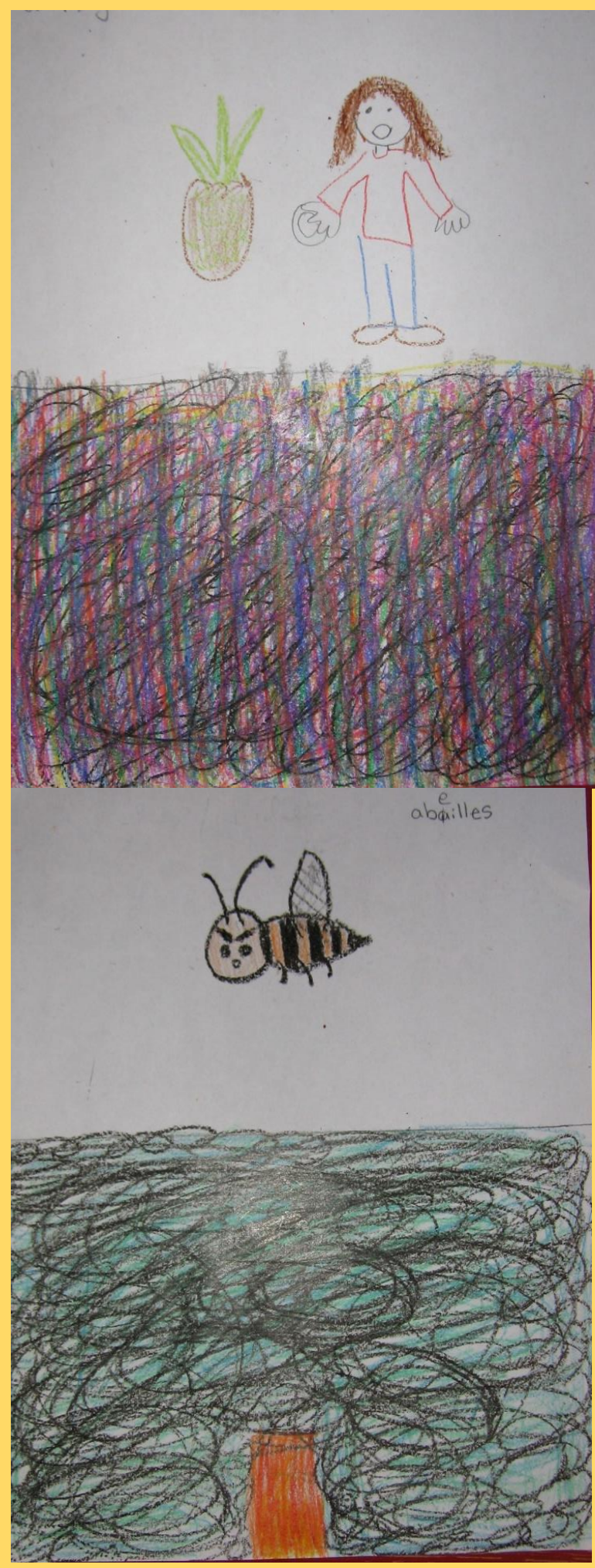

Alysa et Meghan

Breanne et Kylie 


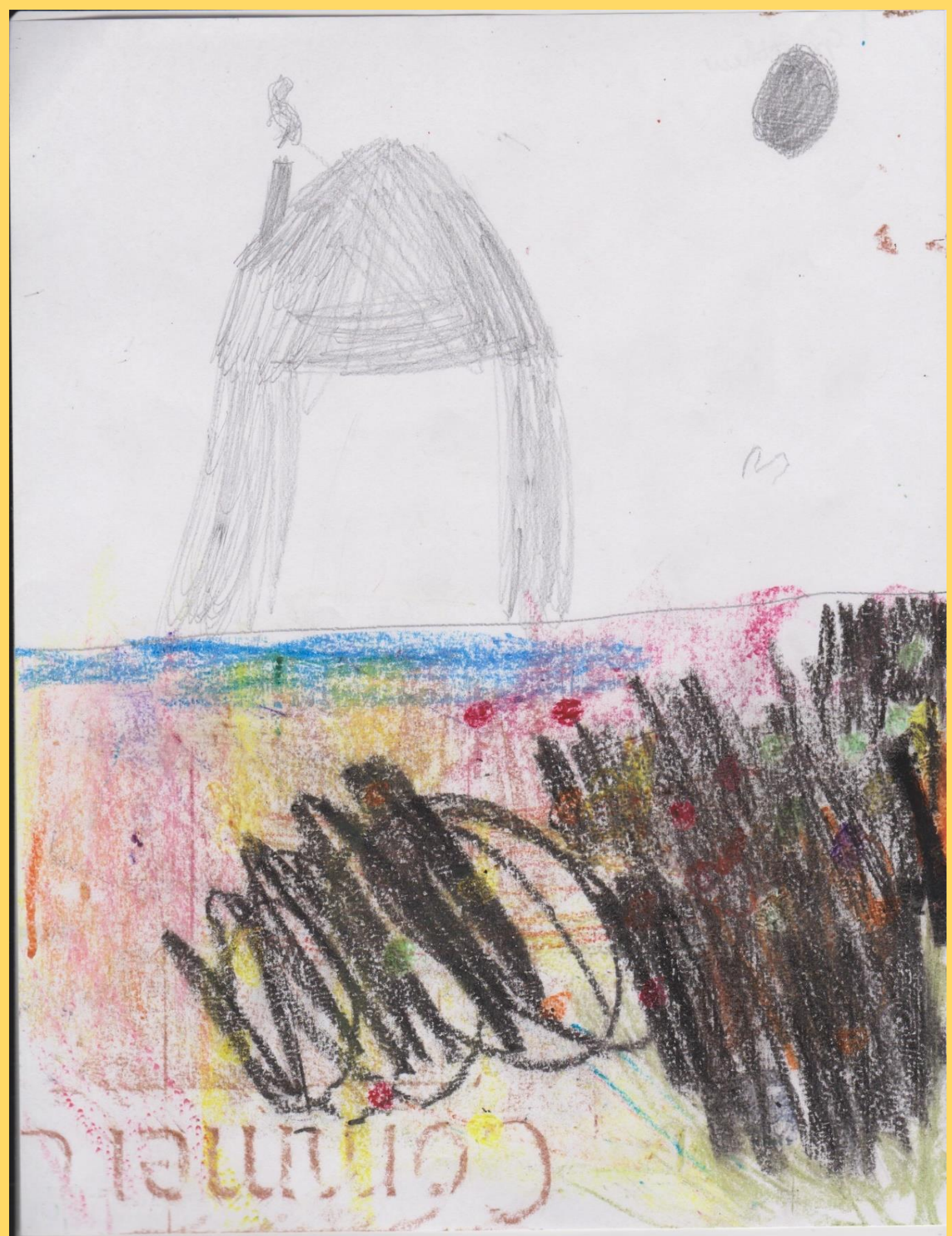




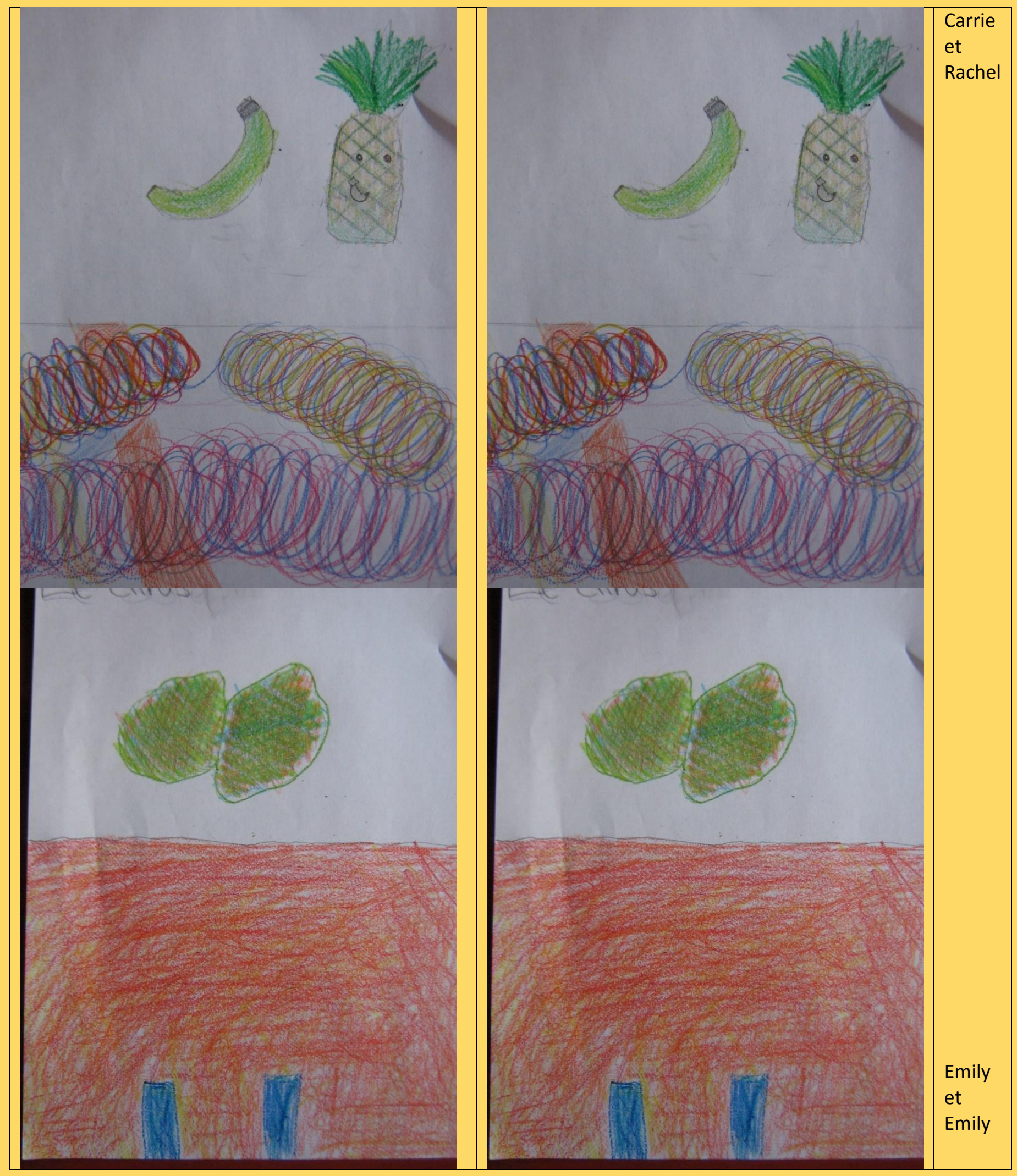




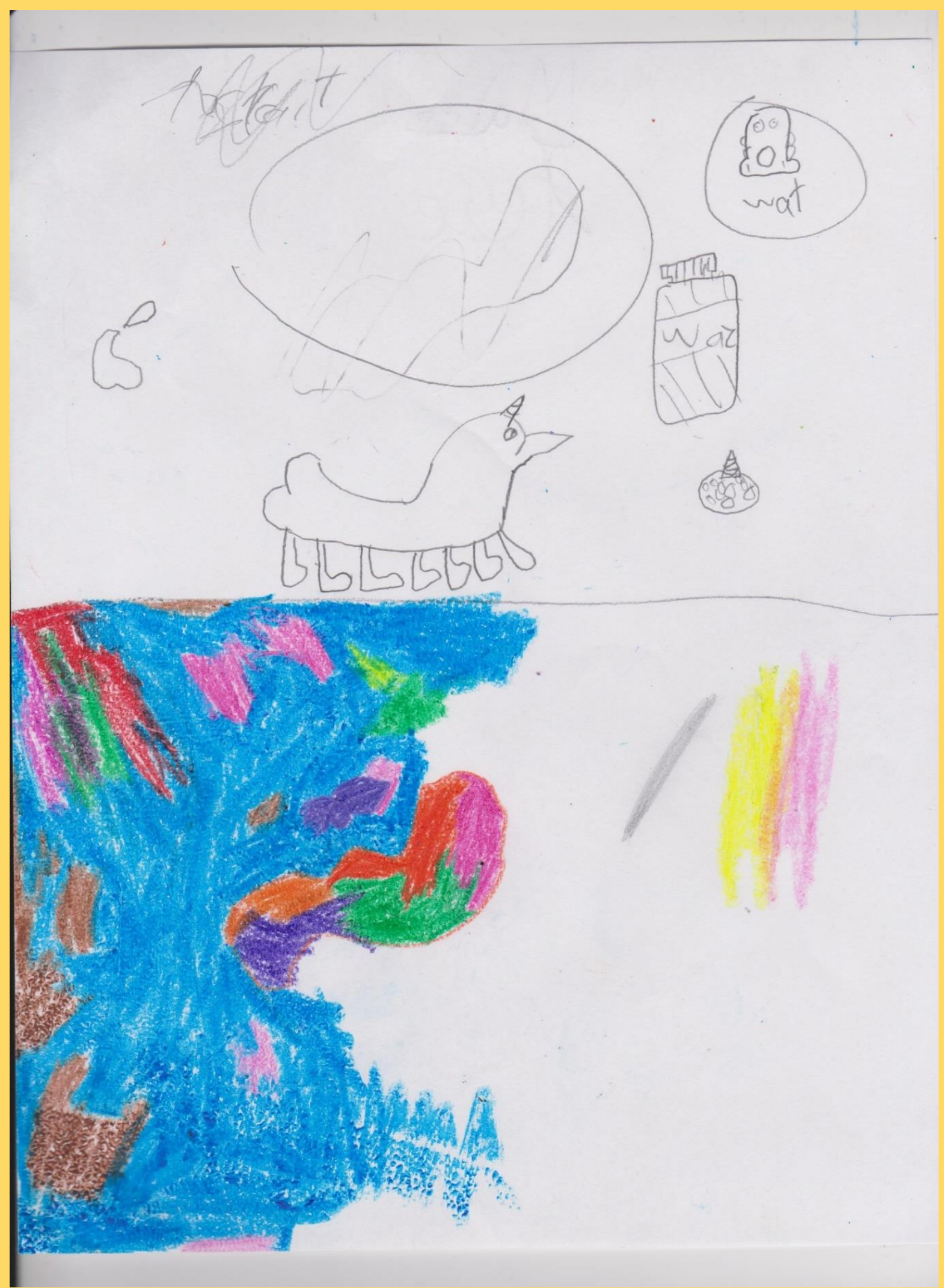

Matteo et Jesse 


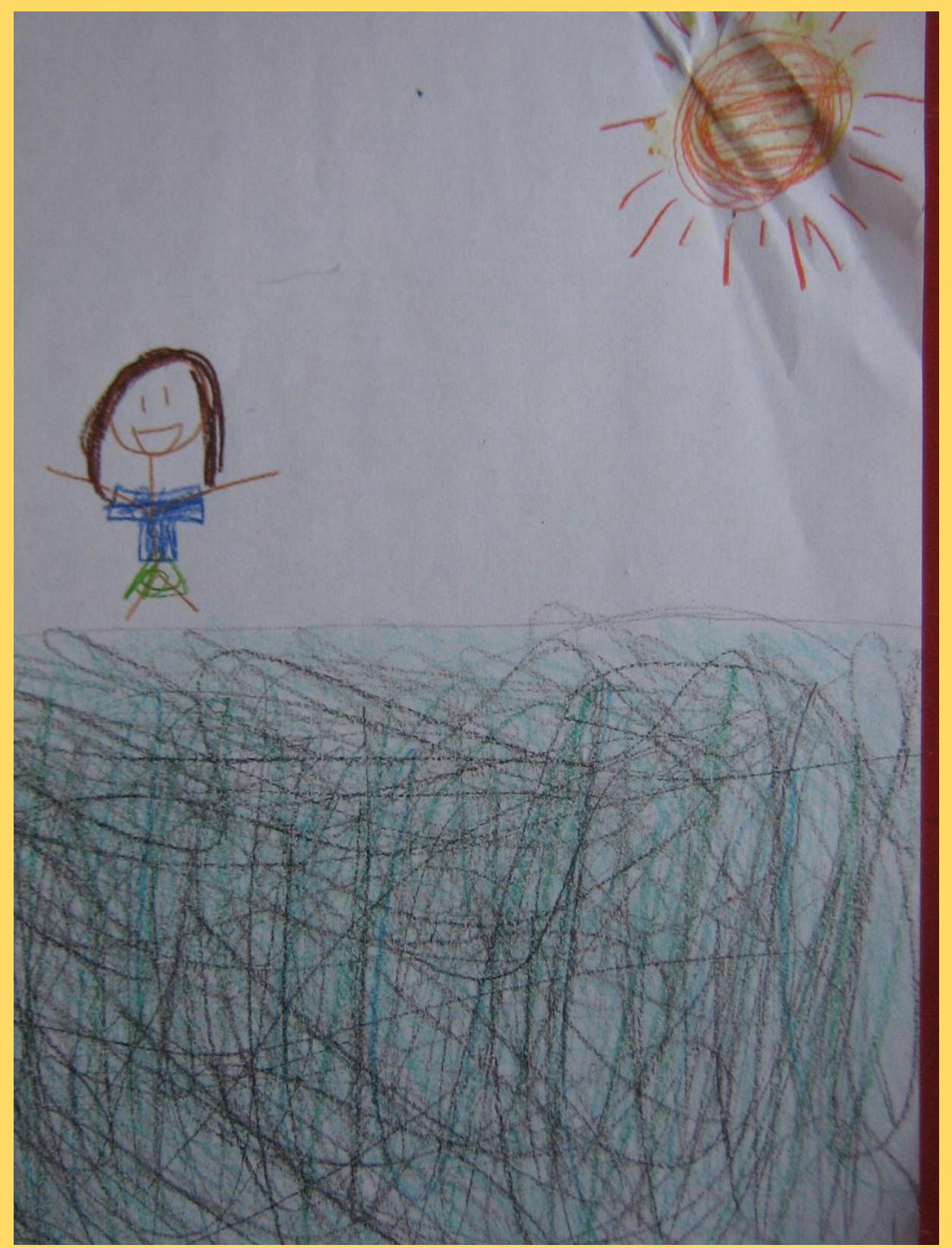

Hannah et Alyssa 


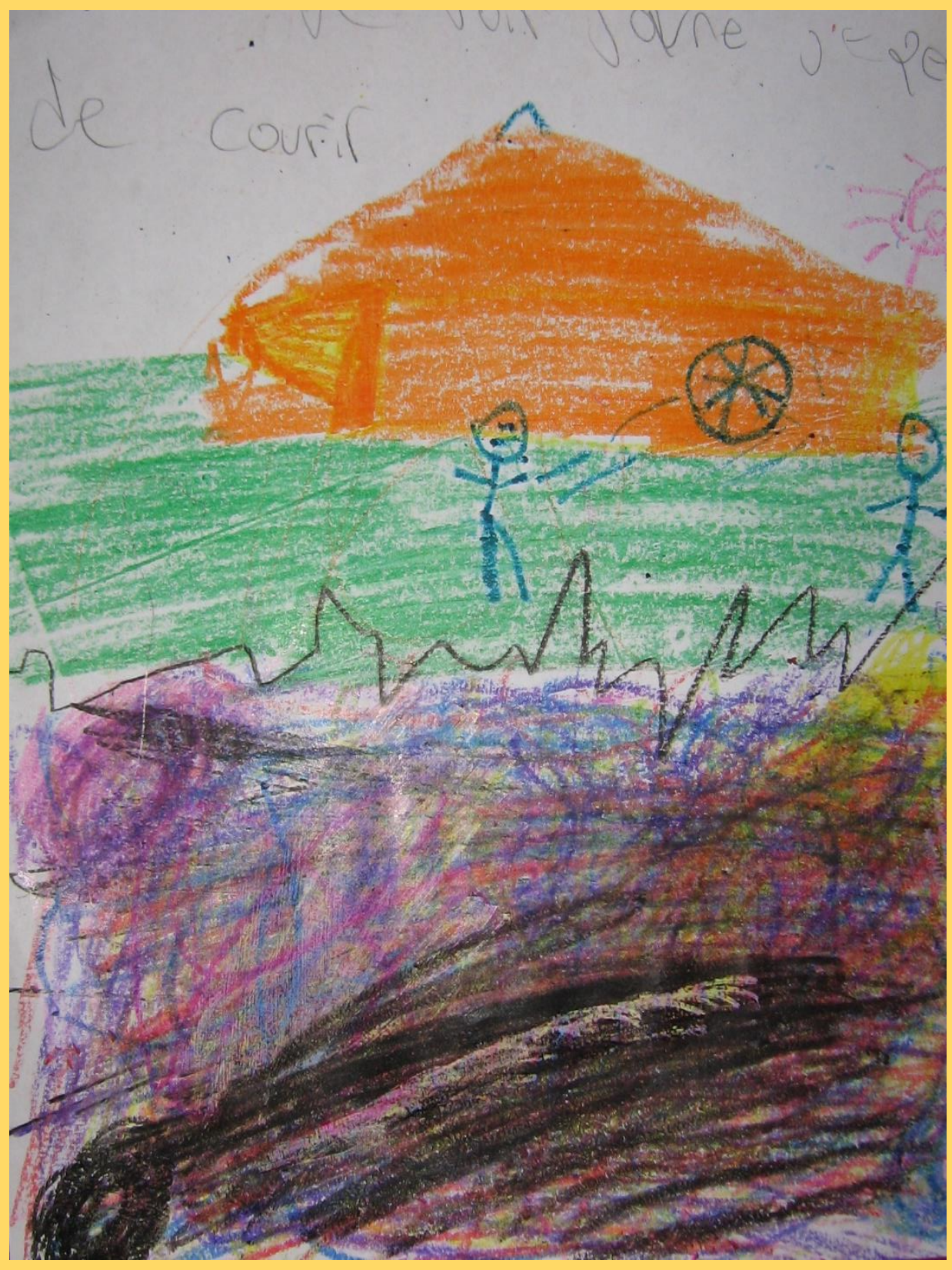

Hunter et Sam 


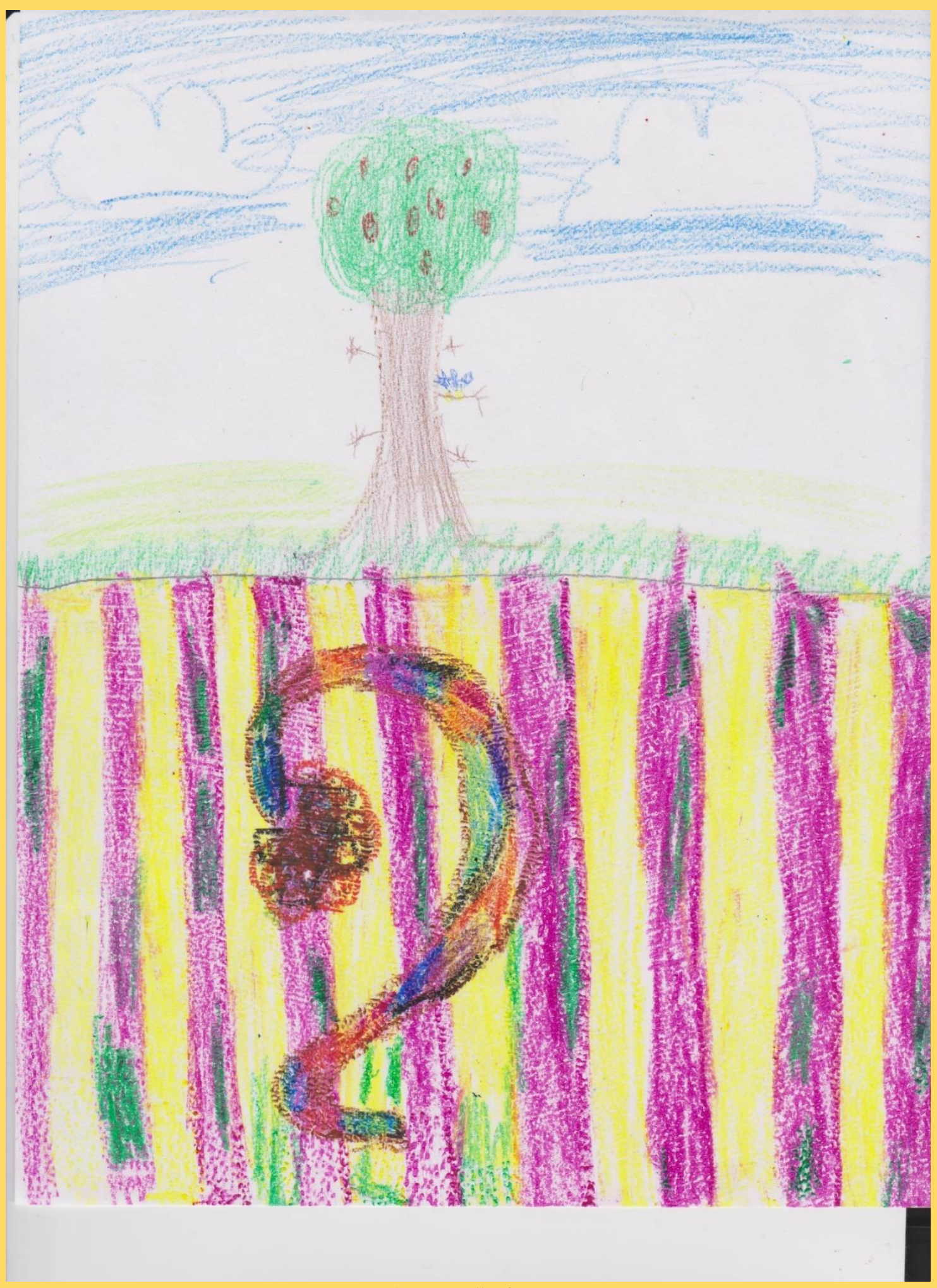

Amy et Sydney 

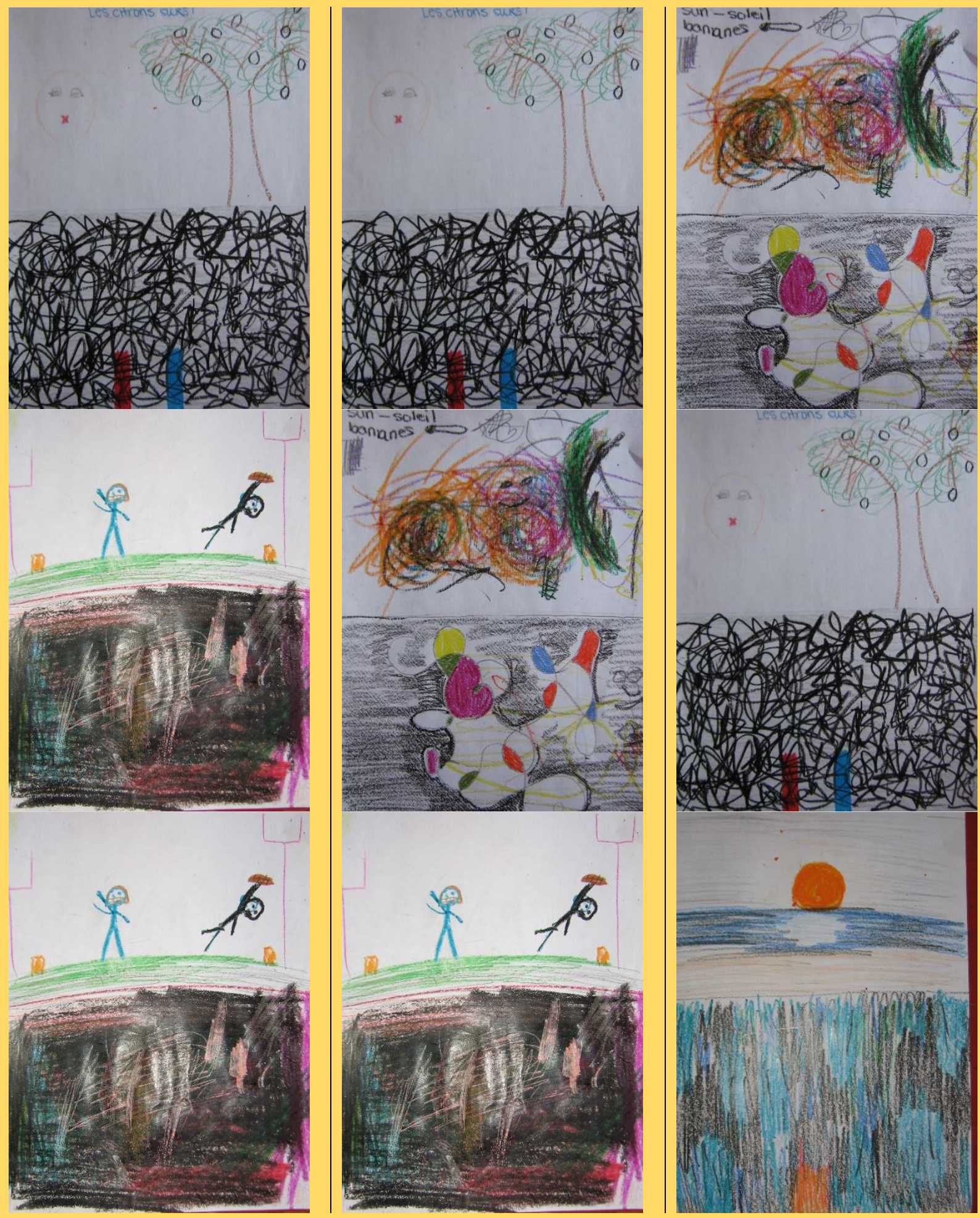

Jasmine et Nicole / Jojo et Reese / Josef et Josh / Nicole et Jasmine 


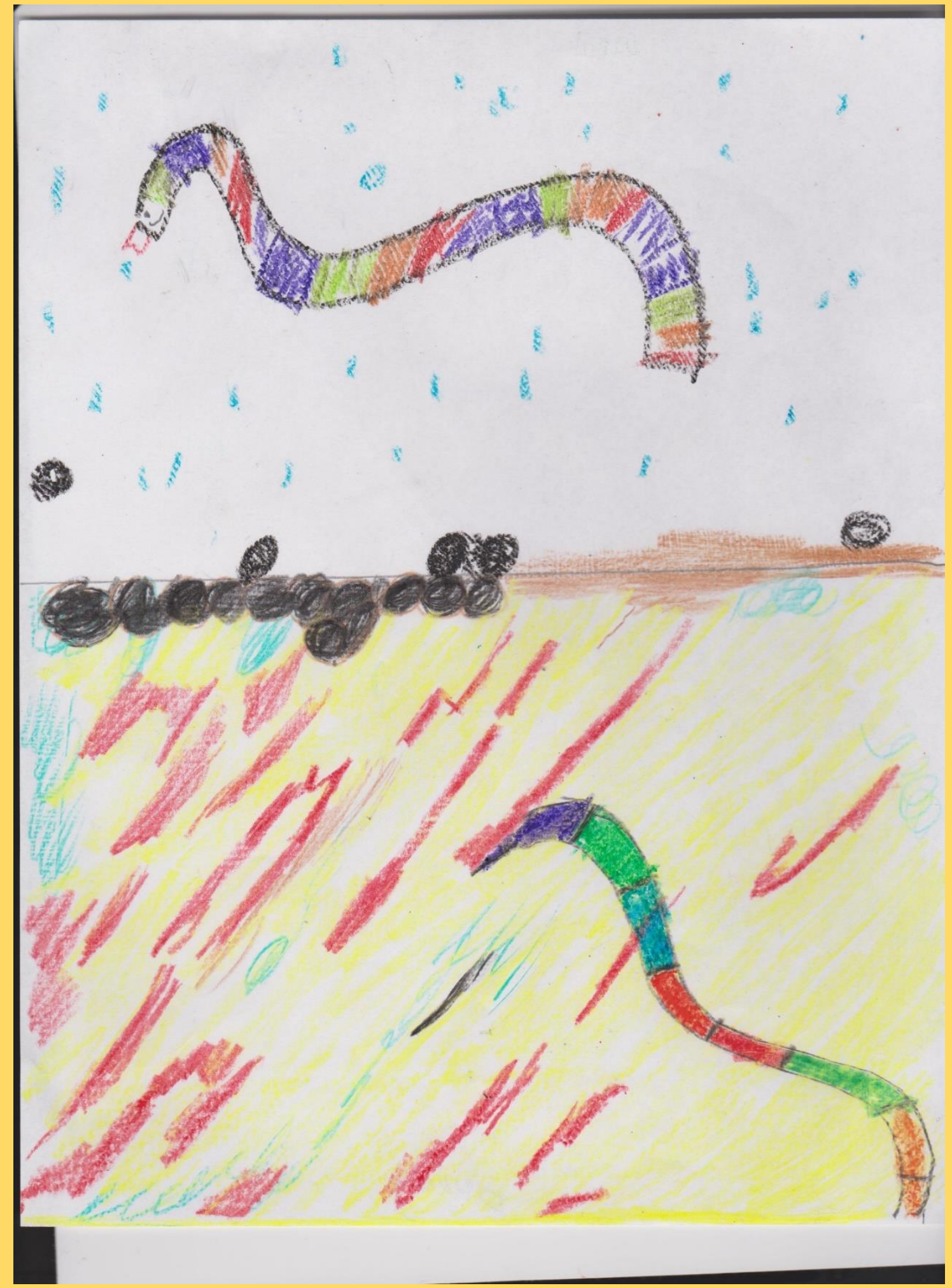

Darah et Emma 
$t i<5.1(2016)$

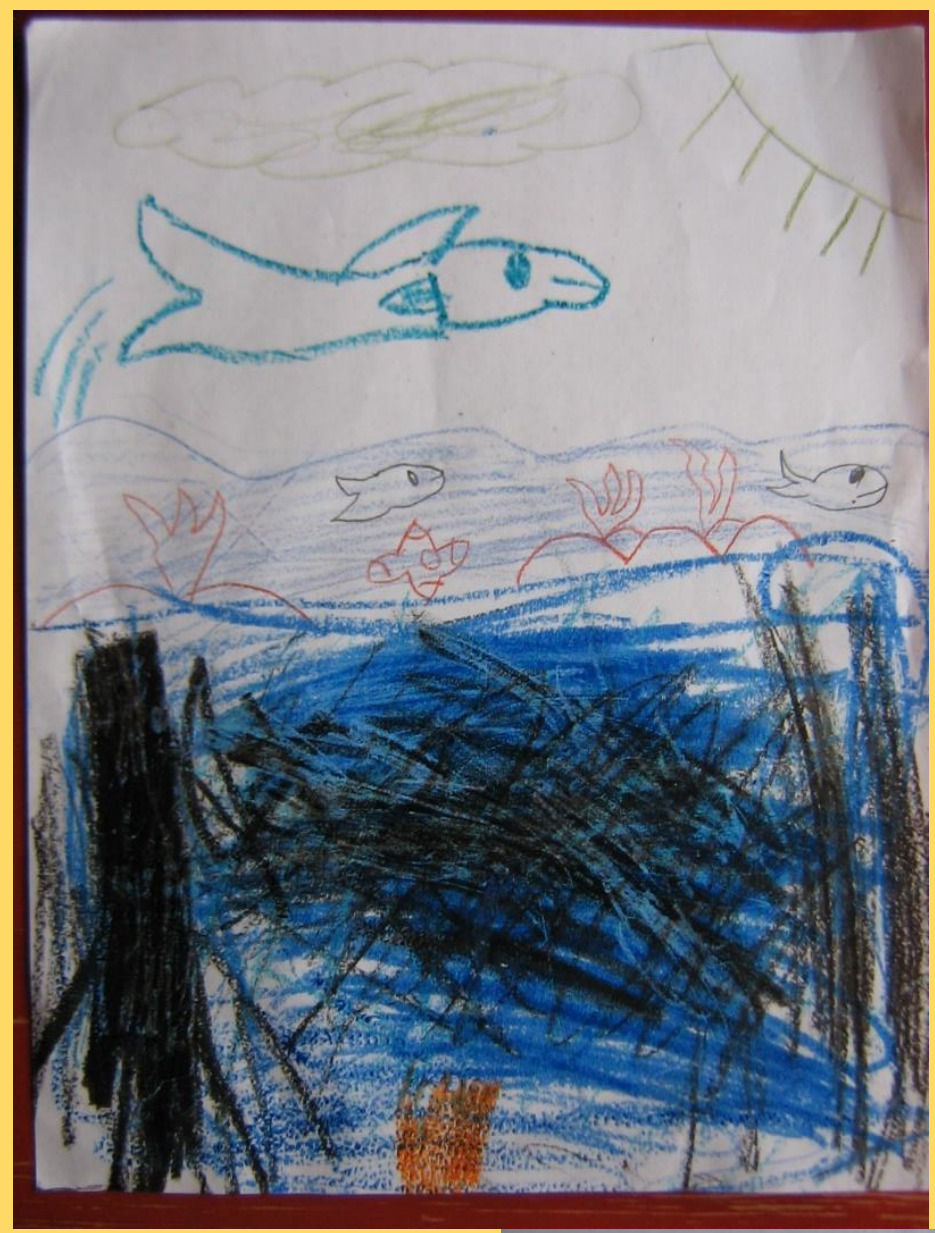

Ava et Hailey

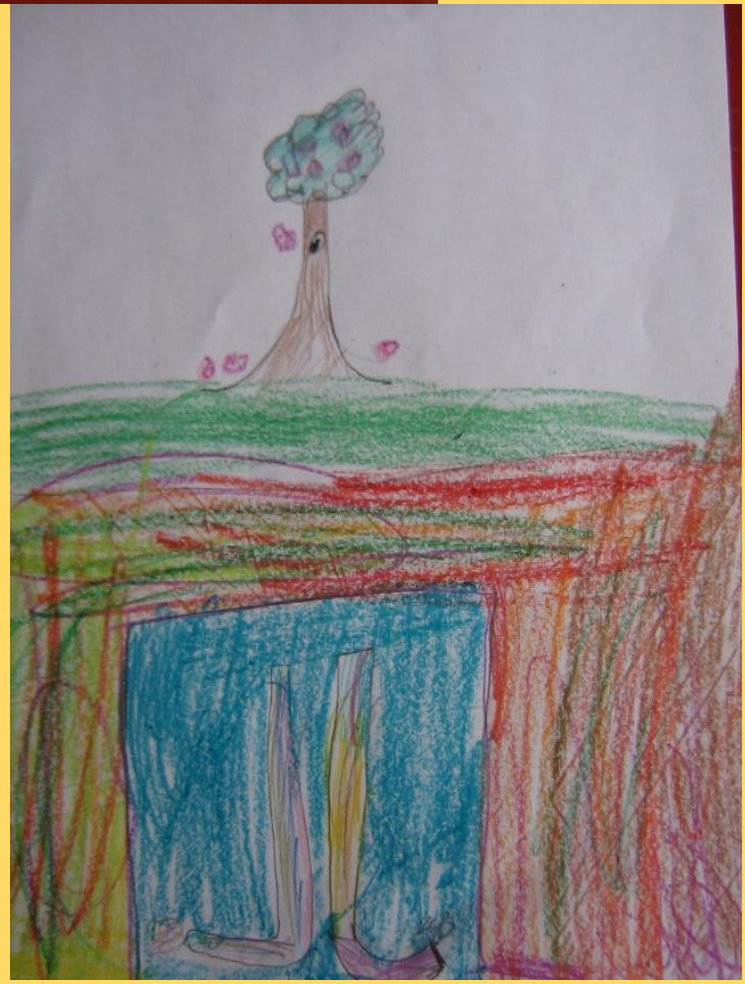

Lorien et Ariana 

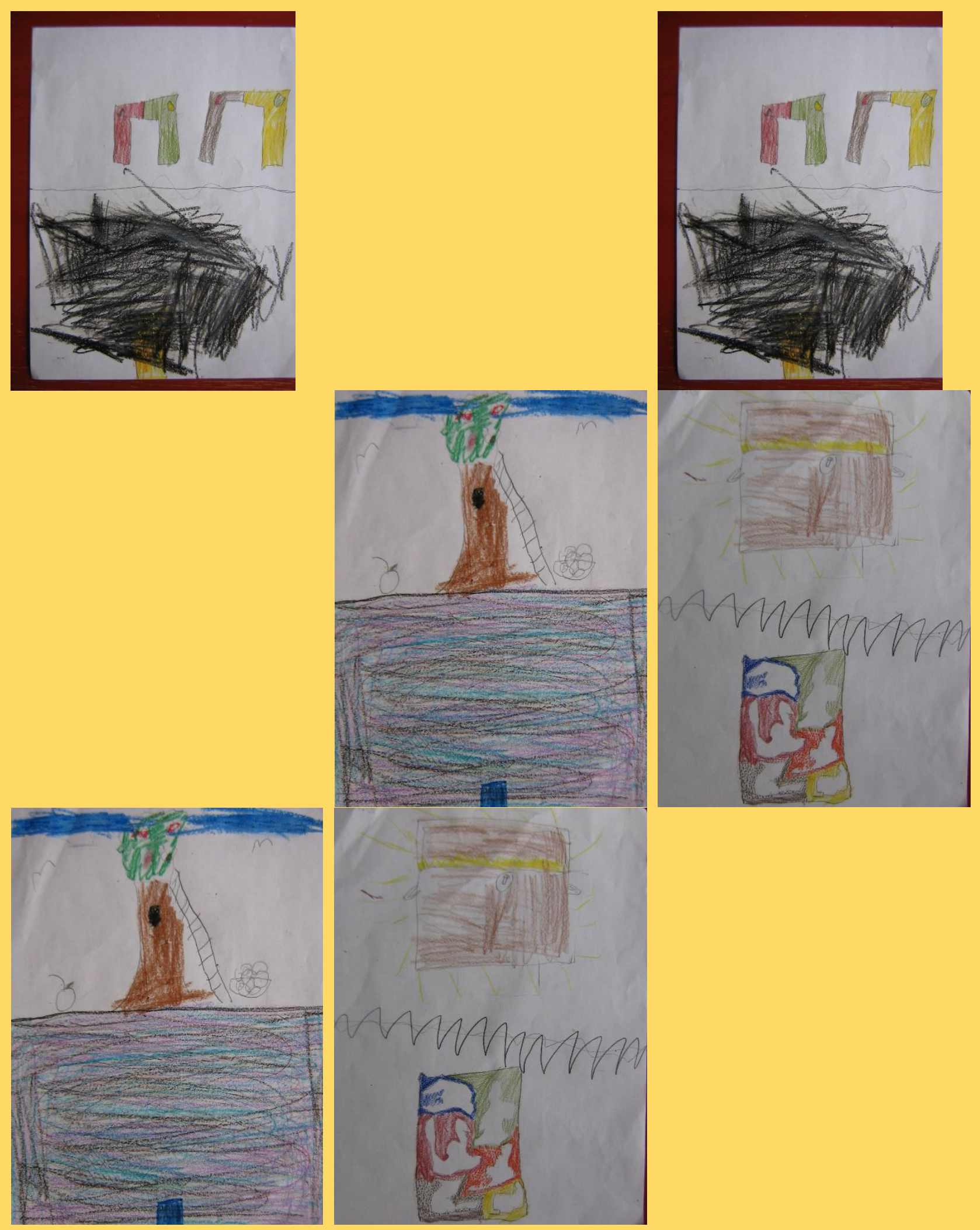

Charles et Owen / Karen et Hailey / Paveng et Isaac 

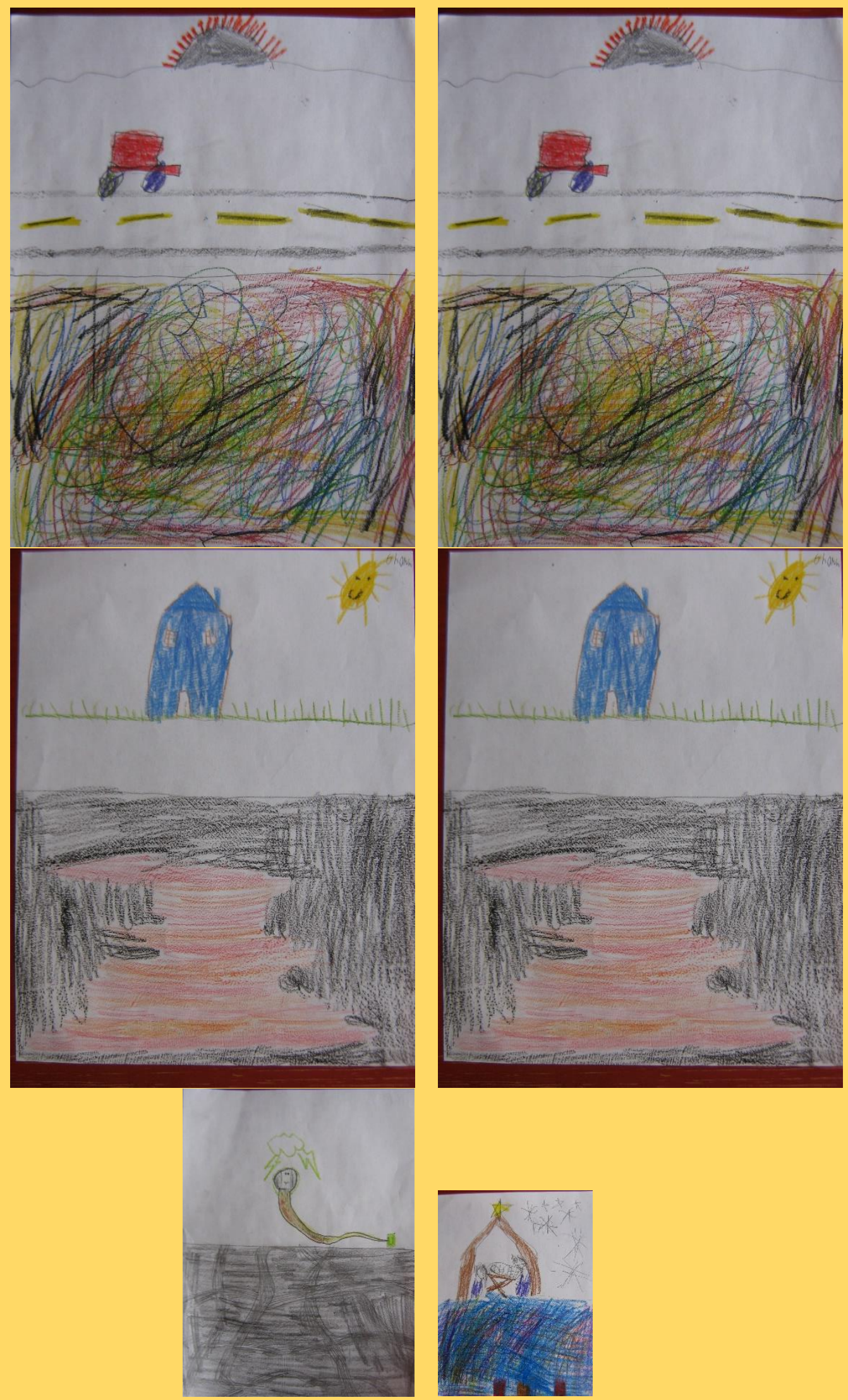

Raohael et Sean / / Michel et Nathan / Nina et Storm 


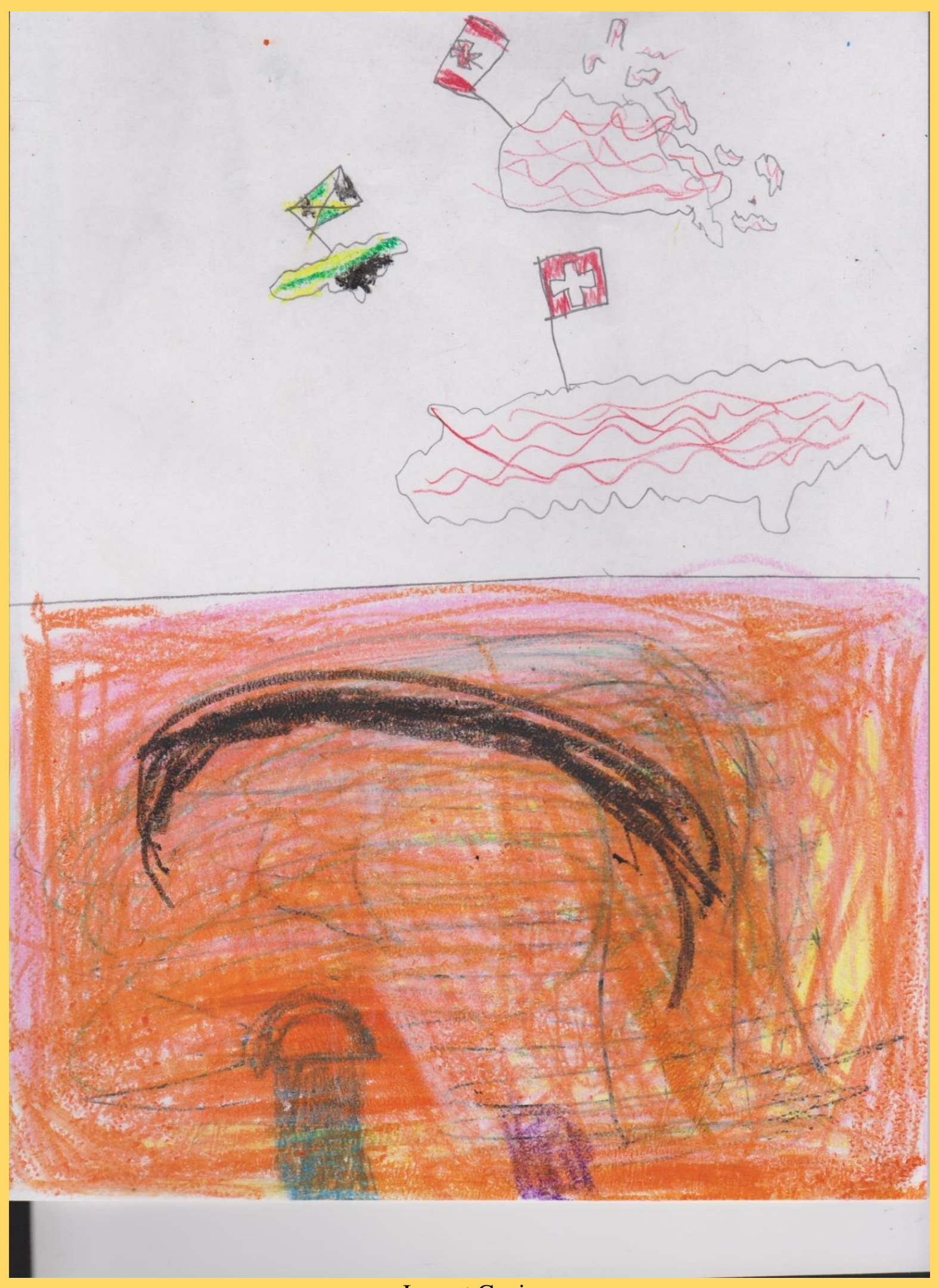

Jona et Gavin 




Clemencia et Mark 

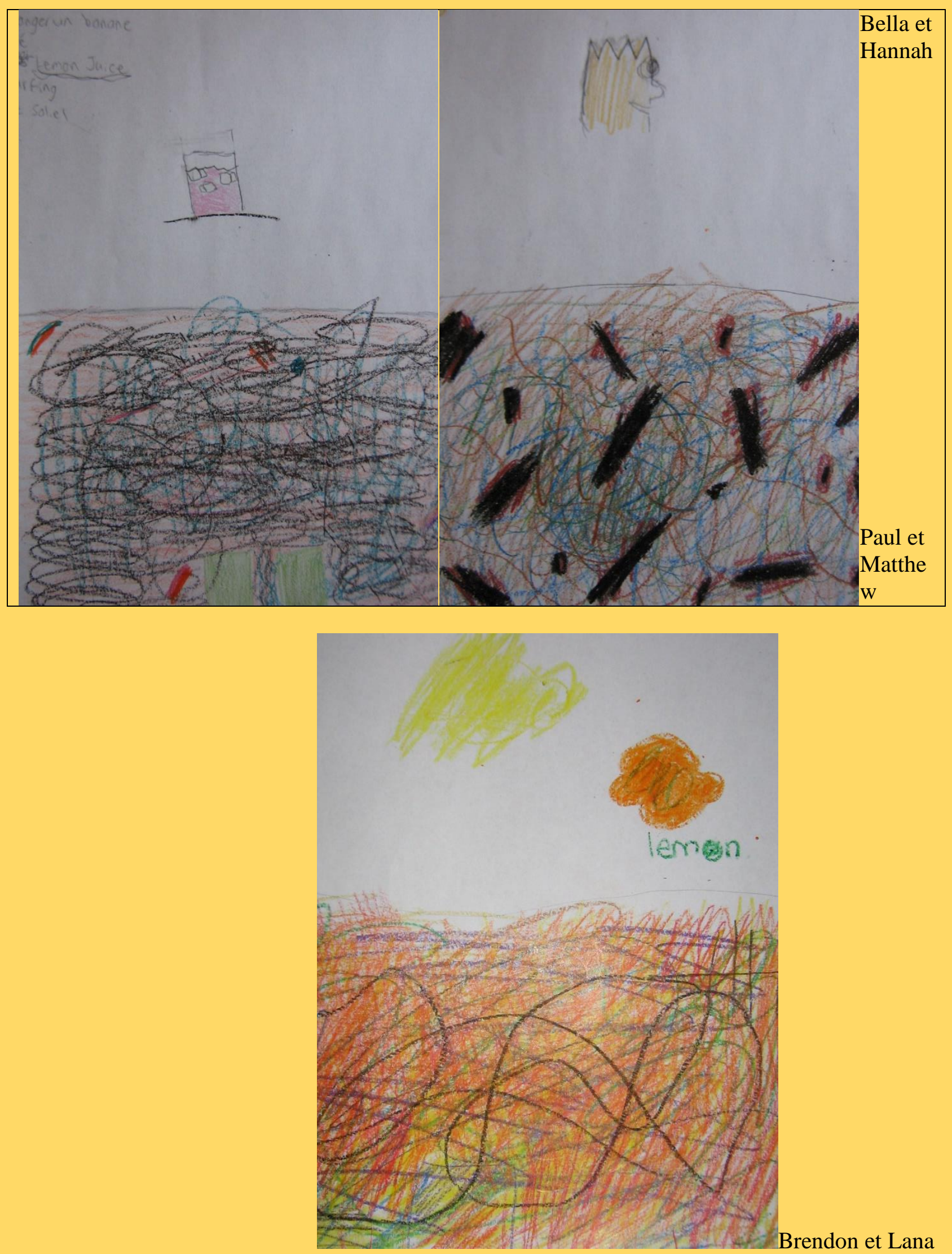


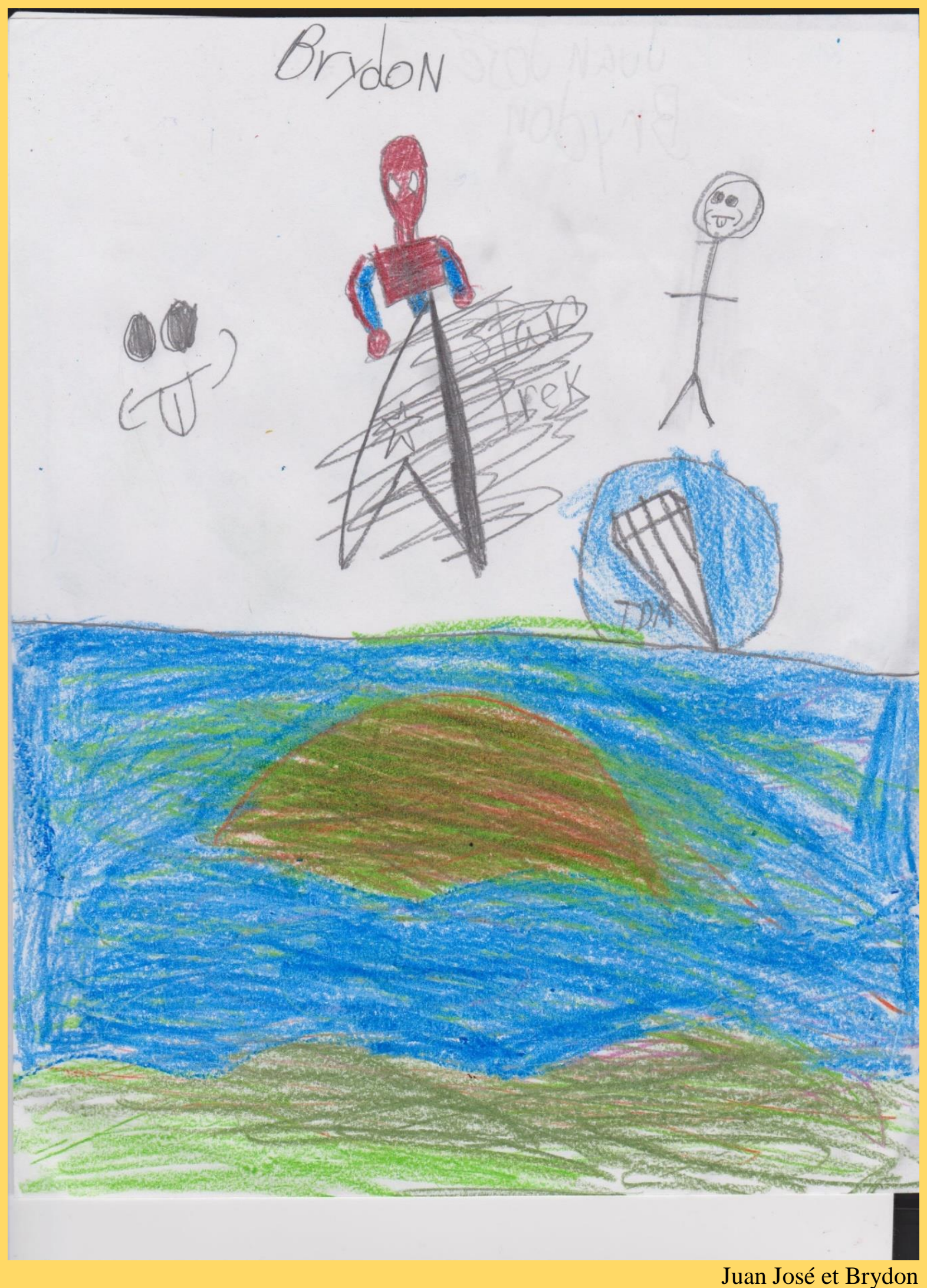



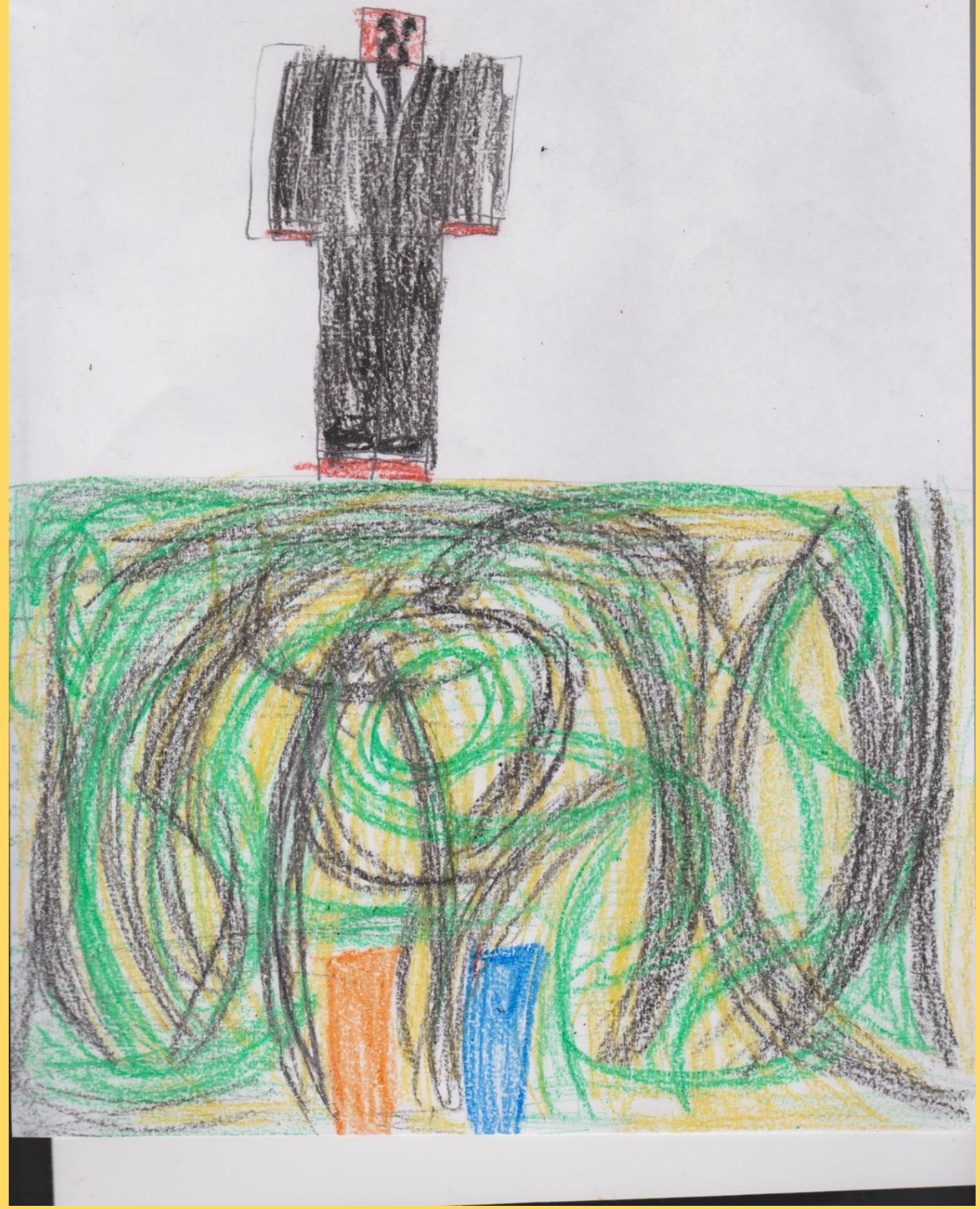

Casey et Xavier 